Journal of Economics and Behavioral Studies

Vol. 4, No. 6, pp. 319-330, June 2012 (ISSN: 2220-6140)

\title{
On Governance and the Demographic Transition
}

\author{
Flaubert Mbiekop \\ Flaubert Mbiekop, International Development Research Centre- IDRC, Canada \\ fmbiekop@idrc.ca
}

\begin{abstract}
It is now conventional wisdom that institutions shape household fertility choices, especially in developing countries. However, deeper insights into the mechanisms at play are still needed. This paper develops a game-theoretical framework with a simple overlapping-generations model to show how a typical household may come to prefer bearing and raising numerous children as a savings scheme for retirement and not rely on conventional outlets for saving when facing weak institutions. On the one hand weak institutions increase the risk that individuals may lose their savings if relying on conventional outlets. On the other hand, childbearing as an investment/savings scheme carries with it the risk that disguised or complete unemployment may prevent grown children from providing the expected old-age financial support. The typical household thus trades off between both types of risks, yet with more control in the latter case, as the likelihood of unemployment can be reduced by carefully selecting a child quality-quantity strategy. Mild conditions are sufficient to show that sound institutions induce less fertility and foster private saving and oldage consumption. A simple voting experiment unveils a tricky socio- economic dynamics whereby wealthier households may have stakes supporting weak institutions.
\end{abstract}

Keywords: Fertility; Governance; Development

\section{Introduction}

Many countries in Sub-Saharan Africa and the Middle East are confronted with a unique development challenge characterized by persistently high fertility rates at the same time that their economies are struggling to generate enough employment and economic opportunities for the fast growing number of young people. Recent estimates suggest that by 2050, Africa will experience the largest percentage of population increase (184 percent) of all regions. It is also estimated that Africa's population (2.1 billion) will be almost three times larger than that of 1998, and ten times than 1950. The expanding population in many African countries certainly presents them with unique opportunities, as witnessed in the recent history of China, India and Brazil. However, in spite of their growth rates, almost none of these economies have been able to make growth inclusive enough to benefit the majority. As the number of young unemployed increases, a growing number of experts are now expressing skepticism over the extent to which countries in Sub-Saharan African can reap the dividends of their demographic experience, hence the call to translate growth into job creation and poverty reduction conveyed by the U.N. Economic Commission for Africa (ECA) and the African Development Bank. ${ }^{1}$ Given the challenges that the current demographic experience is posing to many African countries, one is forced to revisit the causes of current population dynamics in Africa. While the seminal work of three Nobel Prize winners has already hinted at economic factors and motives, another line of explanation has long alluded to the institutional environment people live in. ${ }^{2}$ African countries may be in the unique situation where the same set of policies can enable them to address two different and mutually-reinforcing issues. On the one hand, policies and institutions that promote inclusive growth may allow those countries to reap the demographic dividends of their population growth. On the other hand, improving the business environment by setting up sound institutions and rule of law will trigger the transition of these countries to a new demographic regime with a population growth that is more manageable in terms of social goods provision. In this paper we show that this transition into a new demographic regime can arise from people 
relying more on conventional outlets for saving at the expense of the old-fashioned practice of converting current resources into old-age consumption through childbearing and child-to-parent old-age transfers. ${ }^{3}$

In many of today's developing countries - and especially in Africa - children are viewed, at least partly, as economic investment goods in that an expected return in the form of both child labor and old-age financial assistance underlies child bearing (e.g., Schultz, 1997). With alternative forms of asset accumulation foreclosed (given primitive financial institutions, missing social security plans and old-age pensions), it is assumed that individuals rely on their offspring for old-age security, although children themselves are a risky investment because of early death and unemployment probabilities. While it is usually argued that high fertility arises from missing institutions or limited female wage employment opportunities, the paper's main argument is that even if women had more employment opportunities and the relevant institutions were in place, current fertility trends may persist if institutions lack credibility. We show that when faced with noncredible institutions and the absence of rule of law, people refrain from relying on conventional outlets for saving. ${ }^{4}$ The key message is thus that implementing sound institutions not only contributes to making economic growth more inclusive, but it also slows down population growth endogenously. The paper is structured as follows. Section 2 presents some related contributions to the literature. Sector 3 presents the model and Section 4 the results. Section 5 contains concluding remarks.

\section{Literature Review}

This paper adds to the literature on the interplay of household fertility and the aggregate economy. Some contributions focus on the causal link from private fertility choices to the aggregate economy. Prettner, Bloom and Strulik (2012) for instance show that if the quality-enhancing effect outweighs the negative impact of declining fertility then effective labor supply increases in the subsequent period and stimulates economic growth. However, they also find that the quantity-quality trade-off alone is not quantitatively strong enough to overturn the negative effects of decreasing fertility on effective labor supply; hence their hypothesis that behavioral effects like the emergence of a demographic dividend or the positive response of female laborforce participation to low fertility may be playing out. Other contributions to the literature instead investigate the causal link from the aggregate economy to private fertility choices. For instance Dessy (2000) uses a framework where child labor may be illegal and formal education mandatory to show that there exists a threshold level of parental labor income below which household fertility and income are positively correlated. Below the threshold a typical parent takes advantage of the child labor income to increase household income, hence the incentive for increased fertility. Very few authors have studied household fertility in terms of how the institutional framework that underlies economic activities may actually shape private fertility choices. In a recent contribution to the literature, Galasso et al. (2009) investigate the interplay of pension generosity and the development of capital markets on the one hand, and fertility decisions on the other hand. Using a two-period overlapping-generations model they find that more generous pensions impact fertility attitudes more in countries where people have less access to financial markets. These authors' findings suggest that access to financial markets provides individuals with an alternative to saving through childbearing. The latter in turn explains why an increase in pension generosity does not affect fertility decisions much when people have access to financial markets. Billari and Galasso (2009) also find evidence that two recent Italian pension reforms (the "Amato" reform in 1992 and the "Dini" reform in 1995) have led Italian families to increase their average number of children in response to reduced pension entitlements. These authors' finding show the relevance of the "old-age security" motive for contemporary fertility, but also illustrate the key role of trust and credibility in translating institutional arrangements into fertility choices.

Our paper is motivated by the skepticism that access to financial markets is a necessary and sufficient condition for household fertility to decline. The results of Galasso et al. (2009) hold only to the extent that people have confidence in the financial system and pension-paying institutions or social security that may be

$3 \quad$ Lilard \& Willis (1997) document significant child-to-parent old-age transfers in Malaysia.

$4 \quad$ For instance, insecure property rights may limit investments in land or livestock acquisition. Similarly, in a context of recurrent cases of misappropriation and embezzlement weak judiciary systems can dampen incentives for conventional savings and limit the extent to which individuals take advantage of financial systems or even count on the retirement pension they may be entitled to. 
in place. Should the system not be trustworthy, say because of weak institutions or the lack of rule of law, changes to pension generosity may have little impact on fertility. This paper develops a model with formal and informal sector employment, the latter paying lower wages relative to the former. The typical household designs a child quality-quantity strategy to maximize the probability of modern sector employment for its offspring. At stake is the prospect of larger old-age financial assistance. The premise of the paper is that in the presence of weak institutions, household fertility may not fall even with significantly high incomes. As an implication, the traditional mechanism operating through mothers' opportunity cost of time may not work. This is because current earnings cannot safely be converted into old-age consumption. In such situations, oldage financial assistance remains crucial to the elderly. Understanding this, the typical parent seeks to increase the probability that her offspring can secure well-paid jobs and develops a child quality and quantity strategy. These two features are combined so that children are considered in efficient terms for the labor market contest. One of the many tradeoffs facing each household is illustrated by the model's feature that both the number and the quality of children from the same household are important determinants of the probability to secure well-paid positions, yet these two ingredients underlie competing claims on household resources. The notion that weak institutions affect household fertility decisions is inspired by Chart 1 below. The chart is based on a sample of 108 countries, and it documents a strong negative correlation (to the order of -0.67) between fertility rates and rule of law indexes worldwide. ${ }^{5}$

Chart 1: Rule of Law Indexes and World-wide Fertility Figures

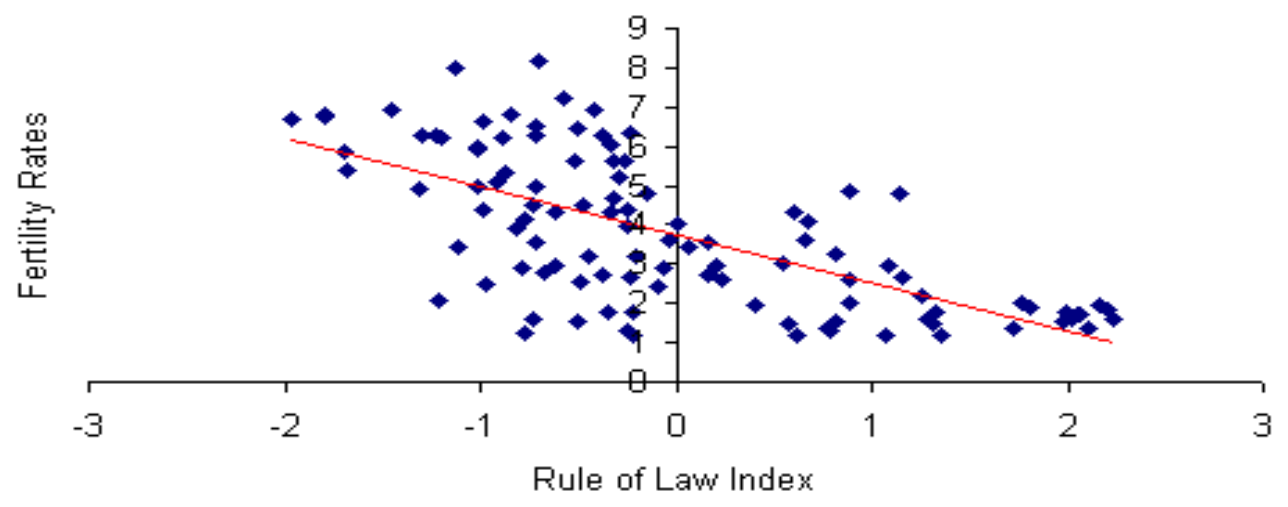

That childbearing serves, as an investment/insurance scheme is all but trivial. If unemployed or if struggling in the informal sector, even well educated children can fail to provide the expected financial support upon growing up. Yet, the paper shows that weak institutions make childbearing more appealing an option when weighing the risks pertaining to conventional outlets of saving against the risk of employment in the informal sector. Unlike most models of children as security assets, which generally emphasize early death risks, the analysis presented here emphasizes labor market uncertainty using five features: (1) a typical household allocates resources to current consumption, saving for old-age consumption, and child rearing. However, depending on institutions' quality, investors may lose their savings and have to rely on their progeny for financial assistance in old age. An index varying between 0 and 1 measures institutions' quality, and as such, the risk associated with formal outlets for saving. Better and trustworthy institutions map into a higher probability that investors can recover their savings. This arises as sound institutions induce more rigorous management both at the macro and the micro level, and brings about contracts enforcement and property

5 Data source: United Nations Population Division http://www.esa.un.org/unppg/ and World Bank Institute, Governance and Anti-Corruption Resource Center.

The Rule of Law indicator is a measure of the extent to which agents have confidence in, and abide by the rules of society. The index, which originally ranges between -2.25 and +2.25 , incorporates perceptions of the incidence of crime, judicial quality and honesty, and the enforceability of contracts, all of which are considered indicators of governance. Kaufmann, Kraay and Mastruzzi (2003) offer an in-depth discussion of the methodology underlying its calculation. 
rights protection, including savers' assets and rights. Our simple overlapping-generations model also accounts for competition over well-paid positions and postulates an endogenous probability to secure such positions. Clearly, the probability of modern sector employment depends on (2) the number, i.e., quantity of children, and (3) the average human capital levels, i.e., quality of children in a given household, as well as (4), the extent of employment rationing in the modern sector as captured by another index varying between 0 and 1. In addition, following Hazan and Zoabi (2006), it is assumed that (5) child-rearing expenditures break down into pure rearing costs, including sheltering, clothing and food on the one hand, and formal education expenditures on the other hand. The model assumes parental altruism away, and each generation plays a "game" whereby each household picks a number of children and invests in their human capital. ${ }^{6}$ Multiplying the number of children in a given household by their average human capital gives the household number of children in efficient units, and reporting the result to the aggregate figures then gives the household probability to access modern sector employment through its progeny. Assuming that elderly parents receive a fraction of their offspring's income, and letting wages be constant, a higher probability of modern sector employment translates into larger transfers, hence parental stake in their offspring economic status. To summarize the findings, under mild conditions, better institutions:

- Induce less fertility at the household level; ${ }^{7}$

- Foster private saving; and,

- Increase old-age consumption.

- Yet a simple voting experiment shows that wealthier households may have stakes supporting weak institutions.

\section{The Model}

Consider an overlapping-generations, two-sector model in which economic activities extend over an infinite number of periods and let $\tau$ denote the generation of individuals born at time $t=\tau$. At the beginning of each period, a new generation of three period-lived, ex-ante homogenous agents is born. The new generation coexists with two other generations, one (which I shall refer to as the active generation), with two periods left to live, and the other (elders), with only one period left. The economy is initially inhabited by $\mathrm{M}_{0}>0$ (active) households, each of which gives birth to $n_{j, \mathrm{x}+1} \in\left[0, n^{\max }\right]$ children at the beginning of the first period, where $n^{\max }$ is the biological maximum and $j \in \Delta_{j} \equiv\left[1, \mathrm{M}_{0}\right]$. Unlike active households, the retired generation plays no active role apart from enjoying old-age consumption. Likewise, children make no decision and enjoy parental supervision. A typical household consists of active parents with their children (if any) and lives apart from retired individuals. A typical individual receives education in the first period of his life (childhood, $\tau$ ), supplies labor in the labor market in the second period (adulthood, $\tau+1$ ), and then retires (old age, $\tau+2$ ). In the third and last period of their life, individuals consume all of their savings. Let $A_{j, \tau+1}$ denote an individual's income net of financial assistance to elderly parents. It is assumed that financial assistance to elderly parents claims a fraction, $\alpha / n_{j, \tau+1}$, out of an individual's labor income, regardless of the sector of employment. $\alpha \in(0,1)$ is an exogenous parameter and $n_{j, \tau+1} \in\left[0, n^{\max }\right]$ the number of children in household $j$. This specification captures the idea that the more siblings, the lower the burden each has to bear providing old-age financial assistance. Adults supply labor either in the modern or in the traditional sector, and there is no child labor in this economy. Each active household plays a pool strategy with respect to openings in the modern sector. Households compete with each other based on their offspring's average human capital (quality) and number (quantity). This is especially the case, as modern sector employment is uncertain even for well-educated individuals. An index of rationing, $\delta \in[0,1]$, summarizes labor market conditions, and takes higher value to signal fewer openings in the modern sector. All else equal, as the index

$6 \quad$ A game approach is appealing in that it offers a nice way to account for such important factors as social norms. In fact, Munshi \& Myaux (2006) draw on a "game" explanation to rationalize why fertility choices have been slow to adjust to external interventions in rural Malaysia.

7 Recent experiences, including those of China (1998 rule of law index of -.22), Indonesia (-.97), and Russia (-.78), suggest that modernization does not necessarily imply the rule of law. Therefore, it is unlikely that the latter might just be acting as a proxy for conventional modernization variables affecting fertility (e.g., female education). 
increases, the probability, $\rho_{j}($.$) , that the labor market contest can be successful to household j$ 's offspring decreases. Clearly, the following endogenous probability of success is attached to household $j$ 's offspring:

$\rho_{j, \mathrm{x}+1}\left(\delta, n_{j, \mathrm{x}+1}, \bar{h}_{j, \mathrm{x}+1}\right)=\left(\frac{n_{j, \mathrm{x}+1} \bar{h}_{j, \mathrm{x}+1}}{\int_{\Delta_{\mathrm{x}}} n_{l, \mathrm{~T}+1}, \bar{h}_{l, \mathrm{~T}+1}}\right)^{\delta}$,

Where $\bar{h}_{j, \mathrm{~T}+1}$ is the average human capital in household $j$ as chosen for children (new generation) by parents (previous generation), $n_{j, \mathrm{x}+1}$ is the number of children in household $j$, and $\int_{\Delta_{x}} n_{L_{s} \mathrm{~T}+1}, \bar{h}_{L_{\mathrm{s} T+1}}$ is the economy's aggregate number of children in efficient terms, i.e., adjusted for their human capital.

In addition to labor market conditions, ${ }^{\delta}$, the above formulation shows that the probability for modern sector employment depends on each household's number and average quality of children relative to the economy's same generation aggregate. It also aligns with Becker and Lewis' (1973) assumption of equal quality for household $j$ 's offspring. Since by construction $\rho_{j \in}(0,1)$ it follows that a child is economic status, $\lambda_{j, \pi+1}$, as captured by the labor income status in adulthood is uncertain. Old-age financial assistance motivates parental investment in the human capital formation of the new generation. Clearly, in addition to making fertility decisions, $n_{j, \tau}+1$, a typical parent from generation $\tau$ chooses how much to consume, $c_{j, \tau+1}$, to save, $s_{j, \tau+1}$, and through formal education expenses, her offspring's average human capital, $\bar{h}_{l, \pi+1}$. An essential feature of this environment is that for saving, individuals have access to a storage technology whereby current resources can be converted into old-age consumption at no cost. However, depending on institutional features as summarized by $\varsigma$, there is a non-trivial probability, $1-\pi(\varsigma)>0$, of losing one's savings. This is because weak institutions pave the way for money embezzlement, misappropriation, spoliation, mismanagement, etc., hence the risk facing investors. Better institutions map into a higher index $\varsigma \in(0,1)$, which in turn raises the probability, ${ }^{\pi}(\mathrm{\varsigma})$, that investors might recover their lifetime savings. ${ }^{8}$ For simplicity, it is assumed that this probability is a linear function of institutions' quality, i.e. ${ }^{\pi}(\varsigma)=\varsigma$. A typical household thus faces the following lottery over old-age consumption:

$$
\left.\Phi_{j, \pi+2} \equiv\left\{\begin{array}{ll}
\pi^{1} \circ a_{j, \pi+2}^{1}, \quad \pi^{2} \circ a_{j, \pi+2}^{2}
\end{array}\right) / \pi^{i} \geq 0 \quad \sum_{1}^{2} \pi^{i}=1\right\},
$$

Where the set of outcomes is given by $\overline{\mathrm{A}}_{j}=\left\{a_{\bar{j}_{\mathrm{i}} \mathrm{T}+2}^{1}, a_{\bar{j}_{\mathrm{j}} \mathrm{T}+2}^{2}\right\}$ and the associated probabilities by $\pi^{1}=\varsigma$, and $\pi^{2}=1-s$, with

$$
a_{s_{j, \mathrm{~T}+2}}^{1}=s_{j, \mathrm{~T}+1}+\alpha \lambda_{j_{0} \mathrm{~T}+1} \text {, and } \quad a_{s_{j, \mathrm{~T}+\mathrm{z}}}^{2}=\alpha \lambda_{j_{0} \mathrm{~T}+1}
$$

Where $\lambda_{j, \mathrm{x}+1}$ is the offspring's (uncertain) income/employment status.

The above formulation reads as follows: With probability $\pi^{1}=\varsigma$, not only does an individual enjoy the oldage consumption level associated with her own saving $s_{j, \tau+1}$ (which she fully recovers), but she also enjoys some extra consumption, $\alpha \lambda_{j_{0} \tau+1}$, that derives from old-age financial assistance provided by grown children and which depends on their economic status. With probability $\pi^{2}=1-\varsigma$, the typical individual loses her lifetime savings and thus must contents herself with whatever old-age financial assistance grown children can provide given their own economic status. This formulation clearly encompasses four possible old-age contingencies, since a grown child's economic status, $\lambda_{j, \pi+1}$, involves employment either in the formal sector or in the informal sector of the economy. The above formulation also calls for two other important remarks. First, although saving is an option, there is no loss of generality in assuming that capital market imperfections prevent people from borrowing. Second, it is assumed that the real return on saving is negligible, i.e., $\mathrm{r} \approx 0$. It then follows that $\beta=1 /(1+r)$ as in Baland and Robinson (2000).

$8 \quad$ The interplay of institutions' quality and old-age financial security was well illustrated by the 2008 financial crisis in the United States. In fact, many retirees lost most of their lifetime savings when Wall Street almost collapsed. Most analysts placed the blame on missing or weakly implemented financial regulation, which they believed exposed investors to the unsafe wealth management practices that triggered a global recession almost as deep as the Great Depression. 
Production technologies and modern sector labor market competition: Both traditional/informal and modern sector firms can produce the numeraire and unique good of this economy. Workers in elastically supply labor to firms in either sector. Due to widespread disguised unemployment as common to many developing countries, it is assumed that demand for labor is perfectly elastic in the traditional sector. The following linear technology also prevails in the informal/traditional sector of the economy: ${ }^{9}$

$F(L)=L$.

As for the modern sector, not only does it generally involve more productive technologies, but also it is also well known for labor market regulations and unionization, all features that introduce a wage differential relative to the traditional sector. Moreover, the modern sector is generally skill intensive, but often offers limited employment opportunities. Hence the following production technology:

\section{$Q(H)=A H$.}

Where $\mathrm{A}>1$ is a productivity parameter and $\mathrm{H}$ human capital. Thus, while there are incentives and potential benefits for human capital accumulation, not all educated individuals get a modern sector job. The traditional/informal sector absorbs the "surplus", though at a lower wage rate. With only one good in this model economy, letting ${ }^{\omega}=\ln (\mathrm{A})$ denote the modern sector's real wage rate, perfect competition in the traditional sector implies that in natural $\log$ terms, ${ }^{\omega}$ can also be interpreted as the wage premium accruing to modern sector workers, hence the stake of the labor market contest. ${ }^{10}$ Clearly, the prospect of one's offspring reaping the wage premium in the labor market explains human capital investment efforts in this economy.

The problem of a typical household: A typical household in this economy faces the following lifetime utility function:

$U\left(c_{j, \pi+1}, c_{j, \tau+2}^{\bar{i}}\right)=u\left(c_{j, \mathrm{~T}+1}\right)+\sum_{1}^{2} \pi^{\bar{i}} v\left(c_{j, \mathrm{~T}+2}^{\bar{i}}\right)$,

where the functions $u$ and $v$ are assumed to be strictly increasing, strictly concave and to satisfy Inada conditions.

A typical household seeks to

$\max _{\left[c_{j, \mathrm{~T}+11}, s_{j, \mathrm{~T}+1}, n_{j, \mathrm{~T}+1}, \hbar_{j, \mathrm{~T}+1}\right]} U\left(c_{j, \mathrm{~T}+1}, c_{j, \mathrm{~T}+2}^{i}\right)$,

subject to the sequence of its periodic budget constraints given below:

$c_{j, \mathrm{~T}+1}+s_{j, \mathrm{~T}+1}+\kappa n_{j, \mathrm{~T}+1}+\bar{h}_{j, \mathrm{~T}+1} \leq A_{j, \mathrm{~T}+1}$,

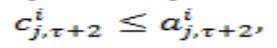

where ${ }^{\kappa}>1$ is a scale parameter and $A_{j_{1} \tau+1}$ is household $j^{\prime}$ s income net of transfers to elderly parents.

The parental maximization program as written above calls for some important remarks. First, individuals are Von Newman-Morgenstern utility maximizes. Second, there is no parental altruism. Third, the current analysis emphasizes a hoarding approach to fertility, since children have to be "stockpiled" in advance, i.e., before the labor market contest starts. Fourth, following Hazan and Zoabi (2006), it is assumed that childrearing expenses break down into pure rearing costs, $\kappa n_{j, \tau+1}$, including sheltering, clothing and food on the one hand, and formal education expenses, $\bar{h}_{j, \tau+1.11}$ Therefore, in terms of equation (1), household $j$ 's children will never get a modern sector job unless a positive amount of resources is devoted to their formal education. The above formulation clearly accounts for the quality-quantity trade-off of fertility choices. This is because, given $A_{j, \tau+1}, c_{j, \tau+1}$, and $s_{j, \tau+1}$, increasing the number of children comes at the expense of investments into their human capital ( ${ }^{\kappa n_{j, \tau+1}}$ versus $\bar{h}_{j, \tau+1}$ in the budget constraint). Combining (1), (3), (6), (7) and

9 The modern-sector's wage rate may clearly vary from one generation to the other. However, this dynamics is irrelevant in the current framework as wages are exogenously determined.

10 In fact, given the above production function, perfect competition in the tradition sector implies that real wage amounts to one in that sector. The ratio of modern to traditional real wages then reduces to the modern sector wage, hence the wage differential in logarithmic terms.

11 This analysis clearly assumes that there exists a one-to-one relationship between overall formal education expenses in household $j$ and the average human capital of its offspring. 
substituting the result back into the objective function for an interior solution yields the following maximization program facing household $j$ :

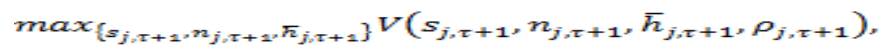

With

$V\left(s_{j, T+1}, n_{j, T+1}, \bar{h}_{j, T+1}, \rho_{j, T+1}\right) \equiv u\left(A_{j, T+1}-s_{j, T+1}-\kappa c n_{j, T+1}-\bar{h}_{j, T+1}\right)$

$+\varsigma v\left(s_{j, \tau+1}+\alpha \omega \rho_{j, \tau+1}\right)+(1-\varsigma) v\left(\alpha \omega \rho_{j, \tau+1}\right)$ The last two terms in the right hand side of $V($.$) call$ for further explanation. Whether the typical individual recovers her lifetime savings or not, transfers from grown children amount to $\alpha \omega \rho_{j, \mathrm{~T}+1}=\omega n_{j, \mathrm{~T}+1} \rho_{j, \mathrm{~T}+1} \alpha / n_{j, \mathrm{~T}+1}$ (from those employed in the modern sector), and 0 (from those employed in the informal/traditional sector). This is because we elected to express wages in logarithmic terms, which implies that for traditional sector workers, $\ln 1=0$, so that $0=$ $0 n_{j, \pi+1}\left(1-\rho_{j, \pi+1}\right) \alpha / n_{j, \pi+1} .^{12}$ In any event the typical elderly parent receives a fraction, $\alpha / n_{j, \pi+1}$, of the earned wage (and, given the logarithmic specification for wages, it turns out that elders receive that fraction of the wage premium). The next section solves the model for parental optimal choices.

\section{Solving the model}

This section first features fertility choices and human capital investments as a double-Nash equilibrium outcome of a non-cooperative game involving the aggregate all families facing exogenously given institutions. Next, it considers a simple voting experiment whereby individuals have the opportunity to vote over the quality of institutions that should govern economic activities.

Fertility, saving and old age consumption: Let household $j$ stand for player $j, j \in\left[1, M_{0}\right]$, and let $N_{j, \pi+1} \equiv[$ $\left.0, n^{\max }\right] \subset \mathbb{N}$ denote the strategy set of player $j$ with respect to fertility, with generic element $n_{j, \pi+1}$. Let also $\Omega \equiv N_{1} \times N_{2} \times \ldots . . \times N_{M_{\tau}}$ denote the space of all feasible strategy profiles, with generic element $n_{\tau+1}$. Since competition over modern sector employment involves the number of household $j$ 's offspring in efficient terms, that feature underlies a second strategic variable in this environment. Hence, let $H_{j, \pi+1}$ denote the strategy set of player $\mathrm{j}$ with respect to human capital investments, with generic element $\bar{h}_{j, \tau+1}$, and $\Phi \equiv \bar{h}_{1 \times}$ $\bar{h}_{2 \times \ldots \times} \bar{h}_{M_{\tau}}$ the space of all feasible strategy profiles, with generic element $\bar{h}_{\tau+1}$. Next, let $V^{\tau j}: N_{j i \tau+1 \times}$

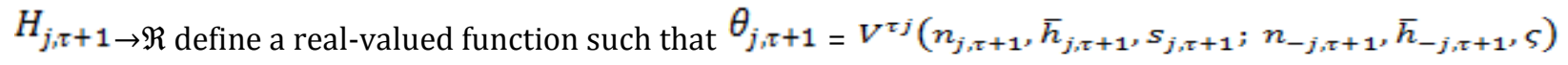
where $\theta_{j, \tau+1}$ denotes the payoff to player $j$ when the strategy profile $n_{\tau+1} \times s_{\tau+1=(}$ $n_{j, \pi+1}, n_{-j, x_{+1}}, \bar{h}_{j, \pi+1}, \bar{h}_{-j, \pi+1}$ ) is played, $n_{-j, x+1}$ and $\bar{h}_{-j, \pi+1}$ denoting the strategy profiles chosen by the aggregate same-generation players other than player $j$.

To keep the model tractable, from now on the following functional forms shall prevail:

Assumption A1: Let $u()=.\ln ($.$) and { }^{v}()=.\ln ($.$) . Let also strong competition prevail in the modern sector, i.e.,$ $\delta=1$. This clearly entails no loss of generality as the focus in this note is not on labor market imperfections. From equation (8), using assumption $\mathbf{A 1}$ and rearranging terms yield the following payoff function for player $j$ :

$$
\begin{aligned}
& \theta_{j, \mathrm{~T}+1}=\ln \left(A_{j, \mathrm{~T}+1}-s_{j, \mathrm{~T}+1}-\kappa n_{j, \mathrm{~T}+1}-\bar{h}_{j, \mathrm{~T}+1}\right) \\
& +\varsigma \ln \left(s_{j, \mathrm{~T}+1}+\alpha \omega \rho_{j, \mathrm{~T}+1}\right)+(1-\varsigma) \ln \left(\alpha \omega \rho_{j, \mathrm{~T}+1}\right) .
\end{aligned}
$$

where $\rho_{j, \pi+1}$ is as defined in (1). I show in the appendix that given $n_{-j}$ and $\bar{h}_{-j, \pi+1}$, the first order conditions of player $j$ 's maximization problem can be rewritten as follows:

$$
\frac{1}{c_{j, \mathrm{~T}+1}}=\frac{\varsigma}{s_{j, \mathrm{~T}+1}+\alpha \omega \rho_{j, \mathrm{~T}+1}},
$$

12 In fact, $\omega n_{j, \tau+1} \rho_{j, x+1}$ gives the number of household $j$ 's children who successfully secure a modern-sector job. $\omega n_{j, x+1}\left(1-p_{j, \pi+1)}\right.$ Thus gives the number of their siblings who end up in the informal sector, in spite of similar levels of human capital. 


$$
\begin{aligned}
& \frac{\kappa n_{j, \mathrm{~T}+1}}{A_{j, \mathrm{~T}+1}-s_{j, \mathrm{~T}+1}-\kappa n_{j, \mathrm{~T}+1}-\bar{h}_{j, \mathrm{~T}+1}}=\frac{\operatorname{s\alpha \omega } \rho_{j, \mathrm{~T}+1}}{s_{j, \mathrm{~T}+1}+\alpha \omega \rho_{j, \mathrm{~T}+1}} \\
& \frac{\bar{h}_{j, \mathrm{~T}+1}}{A_{j, \mathrm{~T}+1}-s_{j, \mathrm{~T}+1}-\kappa n_{j, \mathrm{~T}+1}-\bar{h}_{j, \mathrm{~T}+1}}=\frac{\sec \rho_{j, \mathrm{~T}+1}}{s_{j, \mathrm{~T}+1}+\alpha \omega \rho_{j, \mathrm{~T}+1}}
\end{aligned}
$$

Equation (10) refers to the optimal level of savings, equation (11) to the optimal level of fertility, and equation (12) to the optimal level of human capital investment. The left-hand side (LHS) in equation (10) gives the marginal opportunity cost of conventional savings (less consumption), whereas the right-hand side (RHS) gives the associated marginal benefit in the subsequent period (self-financed old-age consumption). Equation (10) lends support to the argument that institutions matter for investors and drive their arbitrage between current and next period consumption. Likewise, the RHS in (11) gives the marginal benefit of childbearing, whereas in (12) it gives the benefit that derives from an extra unit of human capital investment. The LHSs in each of these two last equations give the associated costs in terms of less consumption in the current period. Using (10), (11), and (12) the Value function reduces to: ${ }^{13}$

$$
\bar{V}\left(n_{j, \mathrm{~T}+1}\right)=(1+\varsigma) \ln \left(A_{j, \mathrm{~T}+1}-\kappa n_{j, \mathrm{~T}+1}\right) \cdot \ln (1+\varsigma)+\varsigma \ln \frac{\varsigma}{1+\varsigma}+(1-\varsigma) \ln \left(\kappa n_{j, \mathrm{~T}+1}\right)
$$

Definition (Double-Nash Equilibrium): $A$ double-Nash equilibrium for the $M_{\tau-\text { player game } G=\left\{N_{1, \tau+1 x}\right.}$

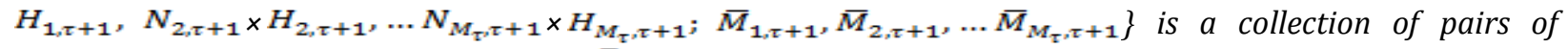
fertility and human capital levels ( $n_{j, \tau+1}^{*}, \bar{h}_{j, \tau+1}^{*}$ ), and a collection of saving levels $s_{j, \tau+1}^{*}, j \in\left[1, M_{o}\right]$, such that for each player $j$ from generation $\tau_{y}$ and given $n_{-j, \tau+1}^{*}$, and $\bar{h}_{-j, \tau+1}^{*}, n_{j, \tau+1}^{*}, \bar{h}_{j, \tau+1}^{*}$ and $s_{j, \tau+1}^{*}$ solve (10) (12). This definition underlies the only theorem in this paper:

Theorem: There exists unique double-Nash equilibrium for the $M_{\tau}$ model economy.

Proof: (Fix Point Theorem) From the proof of Proposition 1 below, it is easy to see that ${ }^{A_{j, \pi+1}}$ and ${ }^{\kappa}$ can always been scaled appropriately for the Value function and the following expression to be positive (first derivative):

$$
\frac{d \bar{V}\left(n_{j, \tau+1} ; \varsigma_{j} A_{j, \tau+1}\right)}{d n_{j, \tau+1}}=\frac{(1-\varsigma) A_{j, \tau+1}-2 \kappa n_{j, \tau+1}}{\left(A_{j, \tau+1}-n_{j, \tau+1}\right) n_{j, \tau+1}}
$$

On the other hand, at $n_{j, \tau+1}=n_{j, \tau+1}^{8}$, we have

$$
\frac{d^{2} \bar{V}\left(n_{j, \tau+1} ; \zeta, A_{j, \pi+1}\right)}{d n_{j, \tau+1}^{2}}=\frac{-2 \kappa-\left(A_{j, \tau+1}-2 n_{j, \tau+1}\right)\left[(1-\varsigma) A_{j, \pi+1}-2 \kappa n_{j, \tau+1}\right]}{\left[\left(A_{j, \pi+1}-n_{j, \pi+1}\right) n_{j, \pi+1}\right]^{2}}<0
$$

It follows that one can always parameterize the model such that the Value function is increasing and concave. Thus, for a positive number of children in each household, there is a unique $n_{j, \mathrm{~T}+1}^{*}$ such that $n_{j, \mathrm{~T}+1=}^{*}$ $\bar{V}\left(n_{j, \tau}, 1 ; \zeta_{j} A_{j, \tau}+1\right)$, i.e. increasing function intersecting with a horizontal line at the fixed point. Likewise, proposition 1 below unveils a one-to-one relation between $n_{j, \tau+1}^{*}$ and $\bar{h}_{j, \tau+1}^{*}$, hence completing the proof of a unique pair $\left(n_{j_{2} \tau+1}^{*}, \bar{h}_{j, \tau}^{*}, 1\right)$ that meets the criteria for the double-Nash. This ends the proof. The next result highlights the properties of the double-Nash equilibrium of this economy:

Proposition 1: The Nash equilibrium profiles for the $M_{\tau-\text { player game satisfy }} n_{j, \tau+1}^{*} \equiv \eta_{(\varsigma,} A_{j, \tau+1)}$, $\left.\bar{h}_{j, \tau+1}^{*}=\kappa \eta_{(\varsigma,} A_{j, \tau+1}\right)$, and $\eta_{\zeta}<0$, (ii) $\eta_{A_{j, \tau+1}}>0$.

Proof: Solving $d \bar{V}\left(n_{j, \tau+1} ; \zeta, A_{j, \tau+1}\right) / d n_{j, \tau+1}=0$ yields $n_{j, \tau+1}^{*}\left(\varsigma, A_{j, \tau+1}\right)=(1-\varsigma) A_{j, \pi+1} / 2 \kappa$, which amounts to picking the inflection point of the Value function to be the fixed point and, therefore, the Nash equilibrium of the game.

Next, in the appendix section I show that, $\bar{h}_{j, \tau+1}^{*}={ }_{(1-\varsigma)} A_{j, \tau+1} / 2$.

This ends the proof.

13 The appendix provides the details deriving the Value function. 
Part one replicates the well-known income effect of the standard micro-economic theory of household fertility. Part two formally rationalizes the connection between institutional features and fertility decisions. It shows that weak institutions bring about higher fertility rates. This is because poor institutions discourage conventional savings and child-to-parent transfers need to take over parental savings in financing old-age consumption. However, since there is only limited employment opportunities in the modern sector, old-age consumption might still be negligible, thus parental strategy to widen the potential sources of financial assistance. Furthermore, part two lends support to the intuition that weak institutions may prevent the high opportunity costs for mothers' time mechanism from operating. This is because current earnings cannot safely be converted into old-age consumption, thus causing parents to rely on their children for old-age security. Therefore, in addition to increased non-agricultural employment opportunities for women as often emphasized in the literature, sound institutions may be necessary to induce changes in fertility behaviors in developing countries. Admittedly, the reasoning that better institutions deter human capital investments may seem counter-intuitive at first glance. Yet, to the extent that sound institutions make it more likely to recover one's savings, there might be less of a need for old-age assistance. Thus, in the absence of parental altruism, individuals have no stake in their offspring's employment status as institutions improve. This in turn reduces human capital investments, including the amount of resources devoted to direct child rearing, $\eta_{(\varsigma,} A_{j, \tau+1}$ ), and formal education expenditures, $\bar{h}_{j, \tau+1}^{*}=\kappa \eta\left(\zeta, A_{j, \tau+1}\right)$. As a result the substitution of child quality for child quantity fails to take place. ${ }^{14}$ This paper clearly adds valuable insights into fertility decisions in developing countries by formally modeling the influence of the institutional environment. The next proposition shows that institutional improvements may affect private saving and old age consumption.

Proposition 2: Let $\varsigma \geq \underline{\varsigma}_{\text {g }}$ with $\underline{\varsigma}=1 / 2$, then better institutions spur private saving and raise old-age consumption, i.e., $d s_{j, \mathrm{\tau}+1}^{*} / d \varsigma>0$, and $d c_{j_{0} \mathrm{\tau}+2}^{i *} / d \varsigma>0$.

Proof: Provided in the appendix.

Proposition 2 has important implications for both living standards and economic growth in developing countries. However, with lifetime utility-maximizing agents, one might dread some dynamic inefficiency, since better institutions encourage private saving over child bearing and might lead to over-saving. Thus, featuring the institutional environment that would lead to an optimal trade-off between current and old age consumption is at order.

A simple voting experiment: In this experiment the typical household has the opportunity to vote on the quality of institutions that should underlie economic activities for the $M_{\tau}$ generation of individuals. Substituting the (Nash equilibrium) solution for fertility, human capital and savings back into equation (9) yields the following welfare function for household $j$ :

$W\left(\operatorname{s;n}\left(\varsigma, A_{j, \pi+1}\right), A_{j, \tau+1}\right)=\ln \left(A_{j, \tau+1}-s_{j, \tau+1}^{*}-\kappa n_{j, \mathrm{\tau}+1}^{*}-\bar{h}_{j, \tau+1}^{*}\right)$

$+\varsigma \ln \left(s_{j, \mathrm{~T}+1}^{*}+\alpha \omega \rho_{j, \mathrm{~T}+1}^{*}\right)+(1-\varsigma) \ln \left(\alpha \omega \rho_{j, \mathrm{~T}+1}^{*}\right)$.

Each household must now make a proposal on the value that $s$ should take in the society. The next proposition summarizes the finding:

Proposition 3: Under the maintained assumption that $\varsigma \geq \underline{\varsigma}$, with $\underline{\varsigma}=\frac{1}{2}$, the wealthier the household, the lower its pick for $\zeta$.

Proof: The proof calls upon the Envelop theorem. Clearly, evaluated at $n_{j, \mathrm{~T}+1}^{*}=\eta\left(\mathrm{s}_{\mathrm{s}}, A_{j_{\mathrm{j}} \mathrm{T}+1}\right)$, we have that $d W(\cdot) / d \varsigma=d \theta_{j_{0}+1} / d \varsigma$. It is then easy to show that $\varsigma_{j_{j \mathrm{x}+1}^{*}}^{*}=2 /\left(2+A_{j_{0} \mathrm{~T}+1}\right)$. The result follows by way of differentiation of $S_{j, \mathrm{\tau}+1}^{*}$ with respect to $A_{j, \mathrm{\tau}+1^{*}}$

This ends the proof.

14 Available evidence suggests that wealthier households actually tend to have fewer children and invest more into their offspring's human capital compared to other households; this suggests some parental altruism in the real world - although this remains an unsettled issue among economists. 
Proposition 3 suggests that it might be all but trivial to address the fast growing population problem facing some developing countries, at least to the extent that the institutional environment shapes fertility choices. The results show that unlike other households from the same generation, wealthier households will typically vote for weaker institutions. This follows from the standard income effect, which implies that in the absence of parental altruism, fertility rates and human capital investments should be higher for richer households. In terms of the labor market contest, more and better-educated children increase the likelihood of modern sector employment, hence the comparative advantage of a child born and raised in a relatively wealthy household. As a result, old-age financial assistance is also likely to be higher in such families compared to the average. Proposition 3 ultimately suggests a complex socio-economic dynamics whereby wealthier households have a vested interest limiting upward intergenerational social mobility by opposing institutional improvements. This is because maintaining the status quo, as far as institutions are concerned, increases the probability of an intergenerational, economic status quo. One way for a wealthy, ruling minority class in a developing country to achieve this objective is to oppose any democratic voting because such a system would result in the majority (relatively poor) voting for improved institutions. This result compares to the one derived by Sonin (2003) who finds that when the public protection of property rights functions imperfectly, agents have incentives to invest in private protection. The ability to maintain private protection systems makes the rich natural opponents of public property rights and precludes grass-roots demand to drive the development of the market-friendly institution. The economy becomes stuck in a bad equilibrium with highincome inequality and widespread rent seeking.

\section{Conclusion}

This paper offers an investigation into the causes of fast population growth and highlights the key role of the institutional framework that underlies economic activities. Sound institutions and the rule of law have long been recognized as essential ingredients for a vibrant and thriving economy, mainly as they underpin an environment conducive to innovation, investment and creation. The results in this paper show that sound institutions may actually have more far-reaching effects as they shape household fertility as well, and thus population growth. The debate over ways of making economic growth inclusive in the presence of fast growing populations is a topical one. The challenges associated with the provision of social goods as well as jobs and economic opportunities for all in such instances are now more apparent than ever. Gaining deeper insights into the dynamics of private fertility decisions are therefore of prime importance in order to pull the trigger that may induce the desired behavioral adjustments. This paper shows that with improved institutions in place and sound governance there is less of a need for people to seek old-age financial security through child bearing. As the typical individual relies on conventional outlets for saving and investment, the economy also grows faster. As a result, moderate population growth combines with a thriving economy to make inclusive growth easier to achieve. To the extent that inclusive growth is not just about creating job opportunities for the youth the paper's finding that better institutions foster old-age consumption reinforces the argument by implying decent living standards for the elderly as well.

Acknowledgements: The paper has benefited from comments by Kaushik Basu, Peter McClelland, Cristina Echevarria, participants at the 2007 annual meeting of the Canadian Economic Association at Dalhousie University, the 2008 annual conference of the Global Development Network in Brisbane, the 65th annual conference of the International Institute of Public Finance in Cape Town in 2009, and the International conference on the Economics of the Family in honor of Gary Becker in Paris in 2011. The usual disclaimer applies.

\section{References}

African Development Bank, Organization for Economic Co-operation and Development, United Nations Development Program, United Nations Economic Commission for Africa. (2012). African Economic Outlook 2012: Promoting Youth Employment. OECD Publishing

Baland, J. M. \& Robinson, J. (2000). Is Child Labor Inefficient? Journal of Political Economy, 108(4), 663-679.

Becker, G. S. \& Lewis, H. G. (1973). On the Interaction between the Quantity and Quality of Children. Journal of Political Economy, 81(2), 279. 
Billari, F. C. \& Galasso, V. (2009). What explains fertility? Evidence from Italian pension reforms. Università Bocconi, February.

Dessy, S. (2000). A Defense of Compulsive Measures against Child Labor. Journal of Development Economics, 62(1), $261-275$.

Galasso, V., Gati, R. \& Profeta, P. (2009). Investing for the old age: pensions, children and savings. International Tax and Public Finance, 16(4), 538-59.

Hazan, M. \& Zoabi, H. (2006). Does Longevity Cause Growth? A Theoretical Critique. Journal of Economic Growth, 11(4), 363 - 376.

Kaufmann, D., Kraay, A. \& Mastruzzi, M. (2003). Governance Matters III: Governance Indicators 1996-2002. World Bank Policy Research Working Paper 3106.

Lilard L. A. \& Willis, R. J. (1997). Motives for Intergenerational Transfers: Evidence from Malaysia. Demography, 34(1), 115 - 134.

Munshi, K. \& Myaux, J. (2006). Social norms and the fertility transition. Journal of Development Economics, 80(1), 1- 38.

Population reference Bureau. (2003). World Population Data Sheet, Washington D.C.

Prettner, K., Bloom, D. E. \& Strulik, H. (2012). Declining Fertility and Economic Well-Being: Do Education and Health Ride to the Rescue? IZA Working Paper, 6527.

Schultz, T. P. (1997). Demand for Children in Low Income Countries. Handbook of Population and Family Economics. Edited by M. R. Rosenzweig and O. Stark.1A, chap. 8. Amsterdam: North-Holland.

Schultz, T. P. (1974). Fertility Determinants: A Theory, Evidence, and Application to Policy Evaluation, Santa Monica, California: RAND Corporation.

Sonin, K. (2003). Why the Rich May Favor Poor Protection of Property Rights. Journal of Comparative Economics, symposium issue on Appropriate Institutions for Growth (S.Djankov and A.Shleifer, guest editors), 31-4, 715-731.

\section{Appendix: Proof of Lemmas and Propositions. \\ Proof 1:}

Claim: $\rho_{j, \pi+1}$ is a decreasing function of $\delta$.

Since by definition $a^{x}=\operatorname{expo}[x \ln (a)]$, where ${ }^{x}$ is the variable and $a$ a constant, the probability of modern sector employment can be re-written as follows:

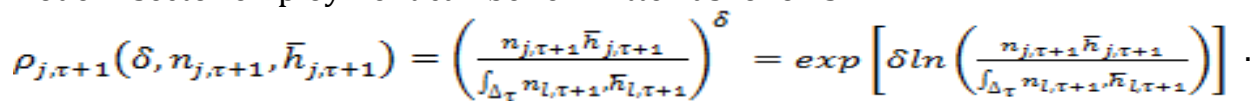

Differentiating the above expression with respect to $\delta$ yields:

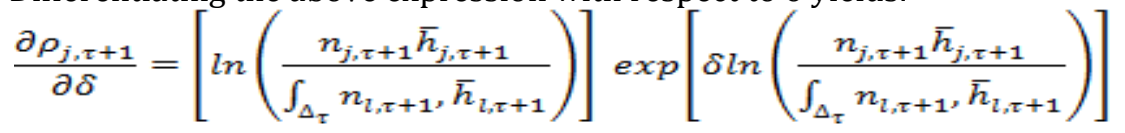

The result then follows from the fact that $\left(n_{j, \mathrm{~T}+1} \bar{h}_{j, \mathrm{~T}+1} / \int_{\Delta_{\tau}} n_{l_{, \pi+1},}, \bar{h}_{h_{,} \mathrm{T}+1}\right)<1$ by definition.

This ends the proof.

\section{Proof 2: Transforming the first order conditions of the maximization problem}

From the payoff function for player $j$ as given in equation (9) and reported below,

$\theta_{j, \tau+1}=\ln \left(c_{j, \mathrm{~T}+1}\right)+\varsigma \ln \left(s_{j, \mathrm{~T}+1}+\alpha \omega \rho_{j, \mathrm{~T}+1}\right)+(1-\varsigma) \ln \left(\alpha \omega \rho_{j, \mathrm{~T}+1}\right)$.

and given $n_{-j, \mathrm{x}+1}$ and $\bar{h}_{-j_{0} \mathrm{x}+1}$, player $j$ 's best response satisfies the following first order conditions for the optimal levels of saving, fertility and child quality respectively:

$$
\begin{aligned}
& s_{j, \mathrm{~T}+1}: \quad \frac{1}{c_{j, \mathrm{~T}+1}}=\frac{\varsigma}{s_{j, \mathrm{~T}+1}+\alpha \omega \rho_{j, \mathrm{~T}+1}}, \\
& n_{j, \pi+1}: \quad \frac{\kappa n_{j, \pi+1}}{c_{j, \tau+1}}=\frac{\left(1-\rho_{j, \pi}+1\right) \varsigma \alpha \omega \rho_{j, \pi+1}}{s_{j, \pi+1}+\alpha \omega \rho_{j, \pi+1}}+(1-\varsigma)\left(1-\rho_{j, \pi+1}\right) \alpha, \\
& \bar{h}_{j, \mathrm{~T}+1}=\quad \frac{\bar{h}_{j, \mathrm{~T}+1}}{c_{j, \mathrm{~T}+1}}=\frac{\left(1-\rho_{j, \mathrm{~T}+1}\right) \varsigma \alpha \omega \rho_{j, \mathrm{~T}+1}}{s_{j, \mathrm{~T}+1}+\alpha \omega \rho_{j, \mathrm{~T}+1}}+(1-\varsigma)\left(1-\rho_{j, \mathrm{~T}+1}\right) \alpha,
\end{aligned}
$$

where $c_{j, \mathrm{~T}+1}=A_{j, \mathrm{\tau}+1}-s_{j, \mathrm{~T}+1}-\kappa n_{j, \mathrm{\tau}+1}-\bar{h}_{j, \mathrm{\tau}+1}$. 
Since $\varsigma_{\in(0,1),} \rho_{j, \pi+1} \in(0,1)$ and $\alpha \in(0.01,0.1)$ (see Lilard and Willis 1997), there is no significant loss of information in assuming that $\varsigma \alpha \rho_{j, \tau+1}^{2} \rightarrow 0$, and $(1-\varsigma)\left(1-\rho_{j, \tau+1}\right) \rightarrow 0$, for all $j$ and $\tau$. Equations (17) and (18) hence reduce to (11) and (12) respectively.

This ends the proof.

Proof 3: Deriving the Value function $\bar{V}\left(n_{j i x+1}\right)$ given by equation (13)

First combine equations (11) and (12) to get

$$
\bar{h}_{j, \mathrm{~T}+1}=\kappa n_{j, \mathrm{~T}+1}
$$

Likewise, combining (10) and (11) using (19) yields

$$
\int_{\Delta_{\tau}} n_{l_{e} \mathrm{~T}+1}^{2} d l=\alpha \omega n_{j_{0, \mathrm{~T}+1}}
$$

Using equation (20), equation (1) can be rewritten as follows:

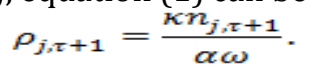

Next, one can substitute equations (19) and (20) back into equation (12) and rearrange terms to get the following expression:

$$
s_{j, \mathrm{\tau}+1}=\frac{\varsigma}{1+\varsigma} A_{j, \mathrm{\tau}+1}+\frac{1+2 \varsigma}{1+\varsigma} \kappa n_{j, \mathrm{\tau}+1} .
$$

Substituting equations (19), (20) and (22) into equation (9) and arranging terms give

$$
\bar{V}\left(n_{j, \pi+1}\right)=(1+\varsigma) \ln \left(A_{j, \pi+1}-\kappa n_{j, \pi+1}\right)-\ln (1+\varsigma)+\varsigma \ln \frac{\varsigma}{1+\varsigma}+(1-\varsigma) \ln \left(\kappa n_{j, \pi+1}\right) .
$$

This ends the proof.

Proof 4: (cf. Proposition 1) $\bar{h}_{j, \tau+1}=(1-\varsigma) A_{j, \tau+1} / 2$.

To prove the result, one first needs to equate (14) to 0 , which gives

$$
n_{j, \mathrm{x}+1}^{*}\left(\varsigma_{s}, A_{j, \mathrm{x}+1}\right)=(1-\varsigma) A_{j, \mathrm{x}+1} / 2 \kappa
$$

Substituting equation (24) back into (19) then gives $\bar{h}_{j_{0} \mathrm{~T}+1}=(1-\varsigma) A_{j_{0} \mathrm{x}+1} / 2$.

This ends the proof.

Proof 5: (cf. Proposition 2)

Claim: Better institutions foster private savings.

To prove the result, one needs to first substitute the Nash solution level of fertility back into equation (22), and then take a first order Taylor series expansion of the resulting equation around $\varsigma=1$. That results into the following expression:

$$
s_{j, \mathrm{x}+1}^{*}\left(\varsigma, A_{j, \mathrm{x}+1}\right)= \begin{cases}(\varsigma-1 / 2) A_{j, \mathrm{x}+1} & \text { if } \varsigma>\underline{\varsigma}, \\ \text { otherwise }\end{cases}
$$

where $\underline{\varsigma}=1 / 2$. The result follows by way of differentiation of equation (25) with respect to $\varsigma$.

\section{Claim: Better institutions foster old-age consumption.}

To prove the result, first combine (7) and (5) using (21), (25) and (24) to get expected old-age consumption at time $\tau+1$ :

$$
\begin{gathered}
E_{\mathrm{x}+1}\left(c_{j, \mathrm{x}+2}\right)=\varsigma\left(s_{j, \mathrm{x}+1}+\alpha \lambda_{j, \mathrm{x}+1}\right)+(1-\varsigma) \alpha \lambda_{j, \mathrm{x}+1} \\
=\varsigma s_{j, \mathrm{x}+1}+\alpha \omega \rho_{j, \mathrm{x}+1} \\
=\varsigma(\varsigma-1 / 2) A_{j, \mathrm{x}+1}+\kappa n_{j, \mathrm{x}+1}^{*}\left(\varsigma, A_{j, \mathrm{x}+1}\right) \\
=[1+2 \varsigma(\varsigma-1)] A_{j, \mathrm{x}+1} / 2
\end{gathered}
$$

Differentiating the above with respect to $\varsigma$ then shows that $\left[\mathrm{d} E_{\mathrm{\tau}+1}\left(c_{j_{\mathrm{j}} \mathrm{\tau}+2}\right) / \mathrm{d} \varsigma\right]>0$, all $\varsigma>\underline{\varsigma}$. 